\title{
SYNERGISTIC AND EFFLUX PUMP INHIBITORY ACTIVITY OF PLANT EXTRACTS AND ANTIBIOTICS ON STAPHYLOCOCCUS AUREUS STRAINS
}

\author{
URMILA $^{1 *}$, SAVITA JANDAIK ${ }^{1}$, JYOTI MEHTA ${ }^{1}$, MANINDRA MOHAN ${ }^{2}$ \\ ${ }^{1}$ Department of Microbiology, Shoolini University of Biotechnology and Management Sciences, Solan, Himachal Pradesh, India. \\ ${ }^{2}$ Department of Biotechnology, Uttarakhand Council for Biotechnology, Haldi, Udham Singh Nagar, Uttarakhand, India. \\ Email: urmila.sharma406@gmail.com
}

Received: 01 July 2016, Revised and Accepted: 05 July 2016

\section{ABSTRACT}

Objective: The purpose of this study was to evaluate the synergistic and efflux pump inhibitory activities of some important medicinal plants collected from Western Himalaya against different strains of Staphylococcus aureus to facilitate the reintroduction of therapeutically ineffective antibiotics back into clinical use.

Methods: Various plant materials were extracted using methanol, ethyl acetate, and water. The dried extracts were screened for synergistic activity by well diffusion method, and efflux pump inhibitory activity for plants extracts exhibiting maximum synergism assessed by berberine uptake assay and ethidium bromide efflux inhibition assay, respectively.

Results: Methanolic extract (ME) and ethyl acetate extracts (EE) of most of the plant extracts showed synergistic activity with ciprofloxacin and norfloxacin, whereas an aqueous extract showed no any synergistic activity. Maximum efflux pump inhibitory activity was observed for ME of Angelica glauca followed by EE of Ficus carica.

Conclusion: ME of A. glauca exhibited potentials of efflux pump inhibition, and thus can, be used as an adjuvant with antibiotics to overcome the problem of drug resistance due to efflux.

Keywords: Staphylococcus aureus, Therapeutically ineffective antibiotics, Synergistic effect, Efflux pump inhibitors.

(C) 2016 The Authors. Published by Innovare Academic Sciences Pvt Ltd. This is an open access article under the CC BY license (http://creativecommons. org/licenses/by/4. 0/) DOI: http://dx.doi.org/10.22159/ajpcr.2016.v9s2.13801

\section{INTRODUCTION}

Staphylococcus aureus is a considerable concern pathogen in both community and hospital settings as it causes mild to severe lifethreatening infections [1]. Besides, its virulence it also shows a remarkable diversity of resistance [2]. Unfortunately, every new antibiotic developed to treat $S$. aureus infections has been accompanied by bacterial antibiotic resistance [3]. Antibiotic resistance is developed by prescribed drug regime's failure and human errors [4]. Numerous defense mechanisms providing resistance to bacteria against the antibiotics include target site modification, antibiotic inactivation, and reduction of the intracellular concentration of the antibiotic, either by a decreased permeability of the cell wall or by the efflux of antibiotic [5] All known mechanisms of drug resistance are overshadowed by effluxmediated resistance. Bacterial efflux pumps can be specific, extruding only one antibiotic or class of antibiotics, or be capable of extruding several classes of antimicrobial compounds [6]. For Gram-positive bacteria, pumps belonging to the major facilitator superfamily (MFS) play a key role in the efflux [7]. NorA multi-drug resistance pump (member of MFS) of $S$. aureus is predominant, chromosomally encoded and can efflux fluoroquinolones, quaternary ammonium compounds, ethidium bromide, rhodamine, and acridines [8]. Reversal of antibiotic resistance or clinical performance of antibiotics can be improved by employing efflux pump inhibitors [9]. The use of plants for treating diseases is as old as the human species. Use and efficacy of medicinal plants significantly contribute to the disclosure of their therapeutic properties $[10,11]$ Plants are natural resources of important phytoconstituents and have been explored as potential sources of antimicrobials. This raises the prospects of obtaining novel chemotherapeutic compounds, especially efflux pump inhibitors. A number of new chemical compounds based on their NorA efflux pump inhibition properties have been investigated, but none of the efflux pump inhibitors have entered clinical trials due to their pharmacokinetic properties and toxic effects. The new active compounds present in medicinal plants give new hope for their future therapeutic usage as an adjuvant of antibiotic [12]. Thus, to overcome the problem of drug resistance due to efflux of ciprofloxacin and norfloxacin, mediated by NorA pump of $S$. aureus, this study was conducted.

\section{METHODS}

Collection of plant materials

The roots, leaves, flowers, and rhizomes of 11 medicinal plants, namely, Angelica glauca, Berberis aristata, Dactylorhiza hatagirea, Ficus carica, Girardinia diversifolia, Malva neglecta, Sinopodophyllum hexandrum, Rubia cordifolia, Sedum glaucophyllum, Solanum americanum, and Valeriana jatamansi were collected from Bhanara, Kullu, Himachal Pradesh, India of North Western Himalaya. The plants specimens have been duly identified and deposited in the herbarium of Botanical Survey of India, Northern circle, Dehradun, Uttarakhand, India.

\section{Processing of plant materials}

Plant materials were washed with distilled water and roots were cut into small bits to facilitate drying. Subsequently, the plant materials were allowed to air dry and grinded into fine powder. The powdered samples were stored in clean glassware containers under refrigerated condition until subjected to further analysis.

\section{Extraction of plant materials}

The each plant material was extracted with methanol (70\%), ethyl acetate $(70 \%)$ and distilled water. $10 \mathrm{~g}$ of plant material was soaked in $100 \mathrm{ml}$ of each solvent for 4 days with shaking at the Orbital Rotary Shaker. The extract was clarified by filtration through Whatman filter paper number 1 and concentrated using a water bath at $40^{\circ} \mathrm{C}$ for $12 \mathrm{hrs}$ [13].

Bacterial strains tested

S. aureus 8325-4 (wild type), K1758 (NorA knockout), and K2378 (NorA overexpressing) were obtained from Northeastern University, Boston, 
USA inoculated in glycerol stocks and maintained on mannitol salt agar plates at Microbiology Research Laboratory Shoolini University, Solan, Himachal Pradesh, India.

\section{Antibiotics used}

Norfloxacin and ciprofloxacin antibiotics which are effluxed by NorA pump of S. aureus were obtained from Sisco Research Laboratories (P) Ltd. and Himedia Laboratories, India, respectively.

\section{Well diffusion method}

The well diffusion assay was performed according to the National Committee for Clinical Laboratory Standards. Mueller-Hinton agar plates were seeded with a 24 hrs culture of the bacterial strains and inoculum was adjusted to an optical disc (OD) of 0.8 abs. Wells of $6 \mathrm{~mm}$ diameter were punched in the agar, and plant extracts (PE) and antibiotics were added in a concentration of $100 \mathrm{mg} / \mathrm{ml}$ and $5 \mu \mathrm{g}$, respectively. Plates were incubated at $37^{\circ} \mathrm{C}$ for $24 \mathrm{hrs}$. For strain where antibiotic did not showed any inhibition zone alone, the combination of PE with antibiotic was calculated on the basis of growth inhibitory indices (GIIs) values and the combination was considered as synergistic, additive and antagonistic when GIIs $>1,1$ and $<1$, respectively, whereas antibiotic showing inhibition alone and in combination, synergistic, additive, and antagonistic activities of PEs with antibiotics were defined with GIIs $>0.5,0.5$, and $<0.5$, respectively [14].

GIIs $=\frac{\text { Zone of inhibition in combination }(\text { antibiotic }+ \text { plant extract })}{\text { Total of zone of inhibition alone }}$

The method was performed in triplicates. After screening for synergistic activity, plants showing maximum synergistic activity were taken for further study.

\section{Screening of efflux pump inhibitory activity Berberine uptake assay}

Berberine uptake assay was performed for the isolation of efflux pump inhibitors [15]. Serial two-fold dilutions of berberine and a PE were mixed in each well of a 96 well microtiter plate. Each row (and column) contained a fixed amount of one agent and increasing amounts of the second agent. The concentrations of berberine (row) ranged from 30 to $0.5 \mu \mathrm{g} / \mathrm{ml}(89-1.5 \mu \mathrm{M})$, while plant compound (column) concentrations ranged from 15 to $0.015 \mu \mathrm{g} / \mathrm{ml}$. Inoculums were added to each well at a final concentration of $5 \times 10^{6} \mathrm{CFU} / \mathrm{mL}$, and plates were incubated at $37^{\circ} \mathrm{C}$ for $24 \mathrm{hrs}$. Growth was assayed by absorption at $600 \mathrm{~nm}$ with a microtiter plate reader. An OD $<0.04$ abs was considered to reveal no bacterial growth. Three replicates were performed for the same.

\section{Ethidium bromide efflux inhibition assay}

Accumulation of ethidium bromide was assessed by ethidium bromide efflux inhibition assay [16]. Sterile microtitre plates were used for this assay. The bacterial inoculum of $175 \mu \mathrm{l}$ was added to each well of 96 well microtiter plates. The $10 \mu \mathrm{l}$ of tested compound added to columns 1-10. $30 \mu \mathrm{l}$ of $100 \mu \mathrm{M}$ EtBr was added to each well. Accordingly, $10 \mu \mathrm{l}$ of positive control (chlorophenylhydrazone) added to column $11.10 \mu \mathrm{l}$ of negative control (dimethyl sulfoxide) also added to column 12. Plates were immediately placed in fluoroscan ascent $\mathrm{Fl}$ and fluorescence of the accumulated ethidium bromide for 30 minutes at excitation $(530 \mathrm{~nm})$ and emission $(600 \mathrm{~nm})$ were determined. Three replicates were performed for each analysis.

\section{RESULTS}

In the present investigation, different extracts (aqueous, ethyl acetate and methanolic) of plants were evaluated for exploration of efflux pump inhibitory activity against $S$. aureus strains. Synergistic activity of each PE with antibiotics (ciprofloxacin and norfloxacin) was evaluated by well diffusion method and efflux pump inhibition for effective plants was assessed by berberine uptake assay and ethidium bromide efflux inhibition assay.
The results of the conducted experiments demonstrated that the most of tested PEs contain potential synergistic activity with antibiotics against $S$. aureus strains; while, aqueous extract of all plants and methanolic extract (ME) and ethyl acetate extract (EE) of B. aristata and S. americanum showed no more synergistic activity.

For NorA overexpressing strain 2378, the antibiotic revealed no any inhibition zone alone. Results given in Table 1 showed that all the ME and EEs of plants showed synergism (GIIs >1). ME of A. glauca and $V$. jatamansi showed maximum $(\mathrm{GII}=1.55)$ and minimum $(\mathrm{GII}=1.04)$ synergistic activities, respectively. For S. aureus 8325-4 and K1758 strains, an antibiotic showed inhibition alone and as well as in combination. The results (Table 1) showed that for NorA wild-type strain, the GIIs values of ciprofloxacin with PEs in combination ranged from 0.60 to 0.75 . Maximum synergism was shown by ME of Sedum glaucophylum (GII=0.75).

In the other hand, the 1758 strain showed the maximum synergism with highest GII value (0.67) with a combination of ciprofloxacin with ME of $S$. glaucophylum and minimum synergism with lowest GII value (0.44) was shown by EE of D. hatagirea (Table 1).

GII values for norfloxacin in combination with PEs ranged from 0.50 to 1.50 (Table 2). Maximum synergism was shown by EE of V. jatamansi (GII=1.50) against K2378 strain, while EE of $S$. hexandrum showed maximum synergism against 8325 -4 strain. In K1758 strain GII values ranged from 0.50 to 0.63 for all tested PEs.

On the basis of synergistic activities of six PEs, namely, $V$. jatamansi (EE), S. glaucophyllum (ME), A. glauca (ME), S. hexandrum (EE), $M$. neglecta (EE), and F carica (EE) which showed maximum synergistic activities were selected for efflux pump inhibitory activity. Berberine is an efflux pump substrate and inhibits growth of bacteria in the presence of efflux pump inhibitor and hence acts as a marker to find out efflux pump inhibitors. A fixed concentration of berberine $(30 \mu \mathrm{g} / \mathrm{ml}$ or $89 \mu \mathrm{M})$ and serial two-fold dilution of PEs $(15-0.015 \mu \mathrm{g} / \mathrm{ml})$ were used in the investigation. An OD $\leq 0.04$ revealed no bacterial growth. The absorbances at different minimum inhibitory concentrations are presented in the Fig. 1.

Six PEs chosen on the basis of synergistic activities were also observed potent in Berberine uptake assay. Out of six plants, A. glauca (ME) showed maximum inhibition of growth followed by $F$. carica (EE) against all tested strains.

In ethidium bromide assay, ethidium bromide is also a substrate of efflux pumps and is effluxed by strains having efflux pumps. In the presence of efflux pump inhibitors, ethidium bromide gets accumulated and showed fluorescence.

In all three test strains, $A$. glauca was showed maximum accumulation of ethidium bromide as well as maximum efflux pump inhibitory activity, while $S$. hexandrum (EE) showed minimum efflux pump inhibition (Figs. 2-4).

\section{DISCUSSION}

The current study initiated because drug resistance is an increasing global concern, and this has been witnessed by increasing resistance among the $S$. aureus population leading to once treatable diseases incurable [17-19]. All known drug resistance mechanisms are overshadowed by the efflux-mediated resistance [6]. Bacterial resistance can be restored by synergistic action of bioactive PEs which is a novel concept and could be beneficial [20]. In the present investigation, methanolic, ethyl acetate, and aqueous extracts of 12 medicinal plants were screened for synergistic activity with two antibiotics (ciprofloxacin and norfloxacin) against $S$. aureus strains (2378 NorA overexpressing strain, 8325-4 wild-type strain and 1758 NorA knockout strain). Among the three extracts, ME and EEs were 
Table 1: Synergistic effect between plants extracts (methanolic and ethyl acetate) with ciprofloxacin (average \pm SD) by well diffusion method

\begin{tabular}{|c|c|c|c|c|c|c|c|c|c|c|c|c|c|}
\hline \multirow[t]{3}{*}{ Plants (part used) } & \multirow{3}{*}{$\begin{array}{l}\text { Type } \\
\text { of } \\
\text { extract }\end{array}$} & \multicolumn{12}{|c|}{ Zone of inhibition (mm) } \\
\hline & & \multicolumn{4}{|c|}{2378 (NorA overexpressing) } & \multicolumn{4}{|c|}{ 8325-4 (wild Type) } & \multicolumn{4}{|c|}{1758 (NorA knockout) } \\
\hline & & PE & $\mathrm{PE}+\mathrm{Cx}$ & $\mathbf{C x}$ & GIIs & PE & $\mathrm{PE}+\mathrm{Cx}$ & $\mathbf{C x}$ & GIIs & PE & $\mathrm{PE}+\mathrm{Cx}$ & $\mathbf{C x}$ & GIIs \\
\hline \multirow[t]{2}{*}{ A. glauca (root) } & ME & $11 \pm 0.8$ & $17 \pm 0.6$ & - & 155 & $13 \pm 0.5$ & $18 \pm 0.5$ & $13 \pm 0.9$ & 069 & $13 \pm 1$ & $19 \pm 0.5$ & $17 \pm 0.9$ & 0.63 \\
\hline & $\mathrm{EE}$ & $12 \pm 0.4$ & $16 \pm 0.8$ & - & 1.33 & $13 \pm 0.8$ & $17 \pm 0.5$ & $13 \pm 0.6$ & 0.65 & $15 \pm 0.3$ & $19 \pm 0.9$ & $17 \pm 0.8$ & 0.59 \\
\hline \multirow{2}{*}{ D. hatagirea (rhizome) } & $\mathrm{ME}$ & $12 \pm 0.4$ & $16 \pm 0.3$ & - & 1.33 & $14 \pm 0.4$ & $18 \pm 0.3$ & $14 \pm 0.3$ & 0.64 & $14 \pm 0.3$ & $19 \pm 0.2$ & $17 \pm 0.3$ & 0.61 \\
\hline & $\mathrm{EE}$ & $18 \pm 0.3$ & $20 \pm 0.4$ & - & 1.11 & $17 \pm 0.2$ & $18 \pm 0.3$ & $12 \pm 0.2$ & 0.62 & $29 \pm 0.4$ & $21 \pm 0.4$ & $19 \pm 0.4$ & 0.44 \\
\hline \multirow[t]{2}{*}{ F. carica (leaves) } & ME & $17 \pm 0.3$ & $19 \pm 0.5$ & - & 1.12 & $18 \pm 0.9$ & $18 \pm 0.8$ & $12 \pm 0.5$ & 0.60 & $18 \pm 1$ & $22 \pm 0.58$ & $19 \pm 0.3$ & 0.59 \\
\hline & $\mathrm{EE}$ & $12 \pm 0.5$ & $17 \pm 1$ & - & 1.42 & $13 \pm 0.3$ & $18 \pm 0.8$ & $13 \pm 0.6$ & 0.69 & $13 \pm 0.8$ & $20 \pm 0.5$ & $18 \pm 0.3$ & 0.65 \\
\hline \multirow[t]{2}{*}{ G. diversifolia (leaves) } & ME & $12 \pm 0.7$ & $15 \pm 0.7$ & - & 1.25 & $12 \pm 0.3$ & $17 \pm 0.6$ & $13 \pm 0.5$ & 0.68 & $14 \pm 0.3$ & $19 \pm 0.3$ & $17 \pm 0.3$ & 0.61 \\
\hline & $\mathrm{EE}$ & $11 \pm 0.2$ & $12 \pm 0.6$ & - & 1.09 & $16 \pm 0.6$ & $18 \pm 0.2$ & $14 \pm 0.5$ & 0.60 & $15 \pm 0.5$ & $19 \pm 0.7$ & $17 \pm 0.6$ & 0.59 \\
\hline \multirow[t]{2}{*}{ M. neglecta (leaves) } & ME & $9 \pm 0.8$ & $12 \pm 0.9$ & - & 1.33 & $12 \pm 0.8$ & $17 \pm 0.6$ & $15 \pm 0.5$ & 0.63 & $13 \pm 0.4$ & $20 \pm 0.4$ & $19 \pm 0.5$ & 0.63 \\
\hline & $\mathrm{EE}$ & $13 \pm 1$ & $18 \pm 1$ & - & 1.38 & $14 \pm 0.7$ & $19 \pm 0.9$ & $14 \pm 0.6$ & 0.68 & $14 \pm 0.7$ & $21 \pm 0.7$ & $18 \pm 0.5$ & 0.66 \\
\hline \multirow[t]{2}{*}{ S. hexandrum A } & ME & $13 \pm 0.3$ & $15 \pm 0.4$ & - & 1.15 & $14 \pm 0.2$ & $17 \pm 0.2$ & $13 \pm 0.3$ & 0.63 & $14 \pm 0.3$ & $20 \pm 0.3$ & $18 \pm 0.3$ & 0.63 \\
\hline & $\mathrm{EE}$ & $16 \pm 0.2$ & $22 \pm 0.2$ & - & 1.38 & $18 \pm 0.3$ & $22 \pm 0.2$ & $13 \pm 0.3$ & 0.71 & $16 \pm 0.6$ & $21 \pm 0.3$ & $17 \pm 0.5$ & 0.64 \\
\hline R. cordifolia (leaves) & ME & $15 \pm 0.2$ & $18 \pm 0.3$ & - & 1.20 & $15 \pm 0.5$ & $18 \pm 0.4$ & $13 \pm 0.3$ & 0.64 & $15 \pm 0.5$ & $19 \pm 0.5$ & $17 \pm 0.4$ & 0.59 \\
\hline \multirow{2}{*}{$\begin{array}{l}\text { S. glaucophylum } \\
\text { (whole plant) }\end{array}$} & ME & $12 \pm 0.6$ & $17 \pm 0.2$ & - & 1.42 & $12 \pm 0.4$ & $18 \pm 0.3$ & $12 \pm 0.4$ & 0.75 & $12 \pm 0.3$ & $20 \pm 0.4$ & $18 \pm 0.2$ & 0.67 \\
\hline & $\mathrm{EE}$ & $16 \pm 0.2$ & $17 \pm 0.4$ & - & 1.06 & $16 \pm 0.2$ & $19 \pm 0.4$ & $14 \pm 0.4$ & 0.63 & $16 \pm 0.5$ & $18 \pm 0.7$ & $16 \pm 0.5$ & 0.56 \\
\hline \multirow[t]{2}{*}{ V. jatamansi (root) } & $\mathrm{ME}$ & $23 \pm 0.4$ & $24 \pm 0.4$ & - & 1.04 & $21 \pm 0.2$ & $22 \pm 0.4$ & $13 \pm 0.2$ & 0.65 & $22 \pm 0.3$ & $22 \pm 0.4$ & $19 \pm 0.3$ & 0.54 \\
\hline & $\mathrm{EE}$ & $13 \pm 0.5$ & $18 \pm 0.3$ & - & 1.38 & $12 \pm 0.3$ & $18 \pm 0.3$ & $13 \pm 0.4$ & 0.72 & $13 \pm 0.3$ & $19 \pm 0.2$ & $17 \pm 0.3$ & 0.63 \\
\hline
\end{tabular}

Values given are mean of three replicates \pm SD. GIIs: Growth inhibitory indices, ME: Methanolic extract, EE: Ethyl acetate extract, PE: Plant extract, Cx: Ciprofloxacin, SD: Standard deviation, A. glauca: Angelica glauca, D. hatagirea: Dactylorhiza hatagirea, F. carica: Ficus carica, G. diversifolia: Girardinia diversifolia, M. neglecta: Malva neglecta, S. hexandrum: Sinopodophyllum hexandrum, R. cordifolia: Rubia cordifolia, S. glaucophylum: Sedum glaucophylum, V. jatamansi: Valeriana jatamansi

Table 2: Synergistic effect of plants extracts (methanolic and ethyl acetate) with norfloxacin (average \pm SD) by well diffusion method

\begin{tabular}{|c|c|c|c|c|c|c|c|c|c|c|c|c|c|}
\hline \multirow[t]{3}{*}{ Plants (part used) } & \multirow{3}{*}{$\begin{array}{l}\text { Type of } \\
\text { extract }\end{array}$} & \multicolumn{12}{|c|}{ Zone of inhibition (mm) } \\
\hline & & \multicolumn{4}{|c|}{$\begin{array}{l}2378 \text { (NorA over } \\
\text { expressing) }\end{array}$} & \multicolumn{4}{|c|}{ 8325-4 (wild type) } & \multicolumn{4}{|c|}{1758 (NorA knockout) } \\
\hline & & PE & $\mathrm{PE}+\mathrm{Nx}$ & $\mathbf{N x}$ & GIIs & PE & $\mathrm{PE}+\mathrm{Nx}$ & $\mathbf{N x}$ & GIIs & PE & $\mathrm{PE}+\mathrm{Nx}$ & $\mathbf{N x}$ & GIIs \\
\hline \multirow[t]{2}{*}{ A. glauca (root) } & ME & $12 \pm 0.4$ & $17 \pm 0.8$ & - & 1.42 & $15 \pm 0.3$ & $19 \pm 0.5$ & $12 \pm 1$ & 0.70 & $14 \pm 0.4$ & $19 \pm 0.5$ & $17 \pm 0.3$ & 0.61 \\
\hline & $\mathrm{EE}$ & $12 \pm 0.3$ & $15 \pm 0.4$ & - & 1.25 & $12 \pm 0.2$ & $15 \pm 0.3$ & $12 \pm 0.8$ & 0.63 & $12 \pm 0.4$ & $17 \pm 0.5$ & $16 \pm 0.5$ & 0.61 \\
\hline \multirow[t]{2}{*}{ D. hatagirea (rhizome) } & ME & $12 \pm 0.2$ & $14 \pm 0.4$ & - & 1.17 & $14 \pm 0.5$ & $17 \pm 0.3$ & $13 \pm 0.2$ & 0.63 & $12 \pm 0.4$ & $15 \pm 0.3$ & $18 \pm 0.3$ & 0.50 \\
\hline & $\mathrm{EE}$ & $12 \pm 0.3$ & $15 \pm 0.3$ & - & 1.25 & $13 \pm 0.2$ & $15 \pm 0.3$ & $12 \pm 0.3$ & 0.60 & $11 \pm 0.4$ & $15 \pm 0.2$ & $17 \pm 0.2$ & 0.54 \\
\hline \multirow[t]{2}{*}{ F. carica (leaves) } & ME & - & - & - & - & - & - & $12 \pm 0.8$ & - & $13 \pm 0.7$ & $16 \pm 0.3$ & $17 \pm 0.4$ & 0.53 \\
\hline & $\mathrm{EE}$ & $11 \pm 0.4$ & $15 \pm 0.5$ & - & 1.36 & $11 \pm 0.5$ & $16 \pm 0.5$ & $12 \pm 0.4$ & 0.70 & $13 \pm 0.5$ & $19 \pm 0.5$ & $17 \pm 0.5$ & 0.63 \\
\hline \multirow[t]{2}{*}{ G. diversifolia (leaves) } & ME & - & $16 \pm 0.2$ & - & - & $12 \pm 0.3$ & $16 \pm 0.4$ & $12 \pm 0.5$ & 0.67 & $15 \pm 0.5$ & $19 \pm 0.4$ & $16 \pm 0.3$ & 0.61 \\
\hline & $\mathrm{EE}$ & - & & - & - & $13 \pm 0.6$ & $16 \pm 0.4$ & $13 \pm 0.3$ & 0.62 & $12 \pm 0.4$ & $17 \pm 0.4$ & $16 \pm 0.6$ & 0.61 \\
\hline \multirow[t]{2}{*}{ M. neglecta (leaves) } & ME & $14 \pm 0.3$ & $16 \pm 0.4$ & - & 1.14 & $15 \pm 0.3$ & $16 \pm 0.4$ & $13 \pm 0.5$ & 0.57 & $14 \pm 0.4$ & $18 \pm 0.3$ & $17 \pm 0.4$ & 0.58 \\
\hline & $\mathrm{EE}$ & $13 \pm 0.5$ & $17 \pm 0.3$ & - & 1.31 & $14 \pm 0.6$ & $18 \pm 0.3$ & $12 \pm 0.4$ & 0.69 & $12 \pm 0.3$ & $19 \pm 0.5$ & $18 \pm 0.2$ & 0.63 \\
\hline \multirow[t]{2}{*}{ S. hexandrum (root) } & $\mathrm{ME}$ & $12 \pm 0.4$ & $15 \pm 0.3$ & - & 1.25 & $12 \pm 0.5$ & $14 \pm 0.5$ & $13 \pm 0.4$ & 0.56 & $14 \pm 0.5$ & $18 \pm 0.3$ & $18 \pm 0.4$ & 0.56 \\
\hline & $\mathrm{EE}$ & $17 \pm 0.4$ & $22 \pm 0.2$ & - & 1.29 & $18 \pm 0.4$ & $22 \pm 0.3$ & $13 \pm 0.2$ & 0.71 & $17 \pm 0.5$ & $22 \pm 0.3$ & $19 \pm 0.3$ & 0.61 \\
\hline \multirow[t]{2}{*}{ R. cordifolia (leaves) } & ME & $12 \pm 0.3$ & $13 \pm 0.4$ & - & 1.08 & $13 \pm 0.3$ & $16 \pm 0.3$ & $14 \pm 0.4$ & 0.59 & $14 \pm 0.4$ & $17 \pm 0.2$ & $17 \pm 0.4$ & 0.55 \\
\hline & EE & $12 \pm 0.4$ & $13 \pm 0.4$ & - & 1.08 & $14 \pm 0.4$ & $16 \pm 0.1$ & $14 \pm 0.2$ & 0.57 & $14 \pm 0.3$ & $17 \pm 0.3$ & $17 \pm 0.4$ & 0.55 \\
\hline \multirow{2}{*}{$\begin{array}{l}\text { S.glaucophylum } \\
\text { (whole plant) }\end{array}$} & $\mathrm{ME}$ & $13 \pm 0.3$ & $17 \pm 0.5$ & - & 1.31 & $13 \pm 0.4$ & $17 \pm 0.4$ & $12 \pm 0.4$ & 0.68 & $15 \pm 0.4$ & $20 \pm 0.5$ & $17 \pm 0.3$ & 0.63 \\
\hline & $\mathrm{EE}$ & - & $16 \pm 0.5$ & - & - & $13 \pm 0.4$ & $16 \pm 0.1$ & $12 \pm 0.3$ & 0.64 & $12 \pm 0.5$ & $17 \pm 0.3$ & $17 \pm 0.5$ & 0.59 \\
\hline \multirow[t]{2}{*}{ V. jatamansi (root) } & ME & $22 \pm 0.3$ & $24 \pm 0.2$ & - & 1.09 & $21 \pm 0.5$ & $22 \pm 0.4$ & $14 \pm 0.5$ & 0.63 & $21 \pm 0.4$ & $21 \pm 0.4$ & $18 \pm 0.3$ & 0.54 \\
\hline & $\mathrm{EE}$ & $14 \pm 0.3$ & $21 \pm 0.3$ & - & 1.50 & $17 \pm 0.4$ & $21 \pm 0.3$ & $14 \pm 0.3$ & 0.68 & $17 \pm 0.3$ & $22 \pm 0.3$ & $18 \pm 0.2$ & 0.63 \\
\hline
\end{tabular}

Values given are mean of three replicates \pm SD. GIIs: Growth inhibitory indices, ME: Methanolic extract, EE: Ethyl acetate extract, PE: Plant extract, Nx: Norfloxacin, SD: Standard deviation, (-): No inhibition zone, A. glauca: Angelica glauca, D. hatagirea: Dactylorhiza hatagirea, F. carica: Ficus carica, G. diversifolia: Girardinia diversifolia, M. neglecta: Malva neglecta, S. hexandrum: Sinopodophyllum hexandrum, R. cordifolia: Rubia cordifolia, S. glaucophylum: Sedum glaucophylum,

V. jatamansi: Valeriana jatamansi

found effective, whereas the aqueous extract not showed any synergistic activity. Consequently, in the study present investigations, some plants exhibited synergistic activity but the results obtained were variable in all the three tested strains and the drugs. G. diversifolia has been found to be synergistic enhancer, though it does not have any antimicrobial properties by yourself, but when taken concurrently with standard antibiotics it enhances the effect of that drug. The plants which showed maximum synergism in the present investigation were V.jatamansi (EE),
S. glaucophyllum (ME), A. glauca (ME), S. hexandrum (EE), M. neglecta (EE), and F. carica (EE) and were selected for efflux pump inhibitory activity. Earlier, several investigations have reported the antimicrobial and synergistic activity of most of the PE such as $R$. cordifolia, Rosamarinus officinalis, Salvia fruticosa, Majorana syriaca, Ocimum basilicum, Syzygium aromaticum, Laurus nobilis, and Rosa damascene against $S$. aureus strains [18,21-25] and have been emerging out as natural sources of potential resistance modifying agents [17,26-33]. All 


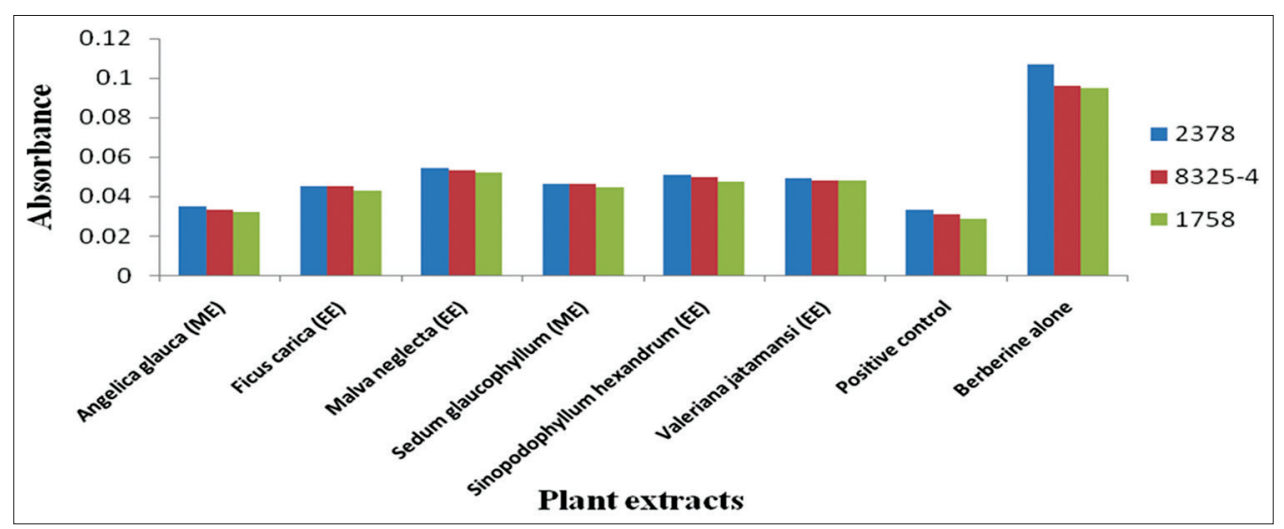

Fig. 1: Absorbance of plant extracts at $89 \mu \mathrm{M}$ of berberine

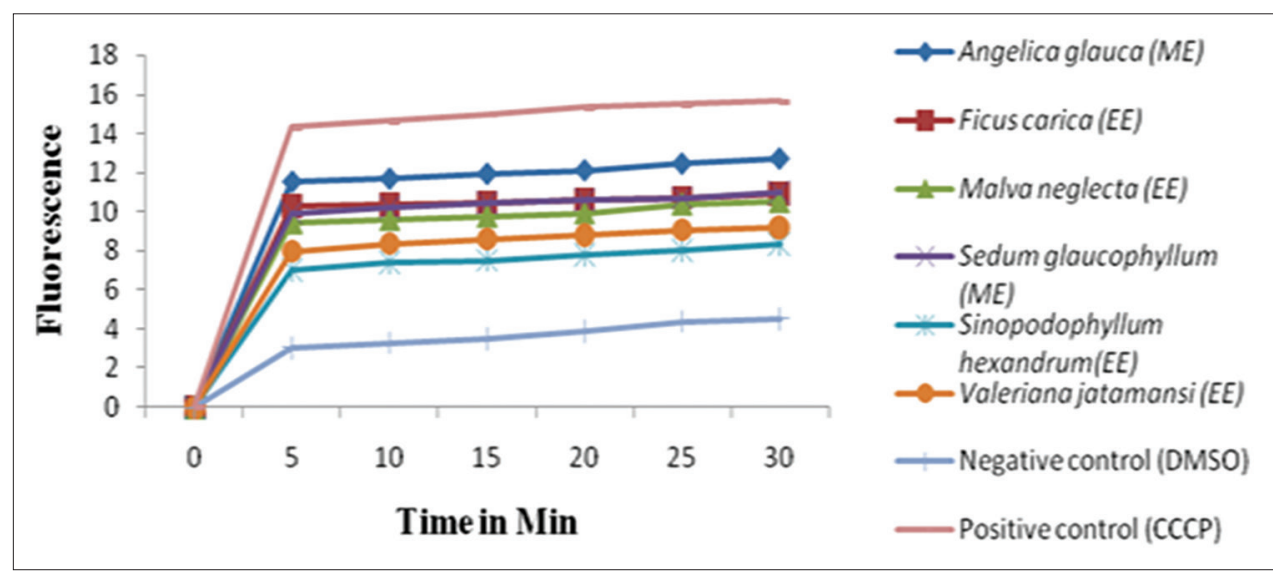

Fig. 2: Effect of plant extracts on accumulation of ethidium bromide by 2378 over expressing strain

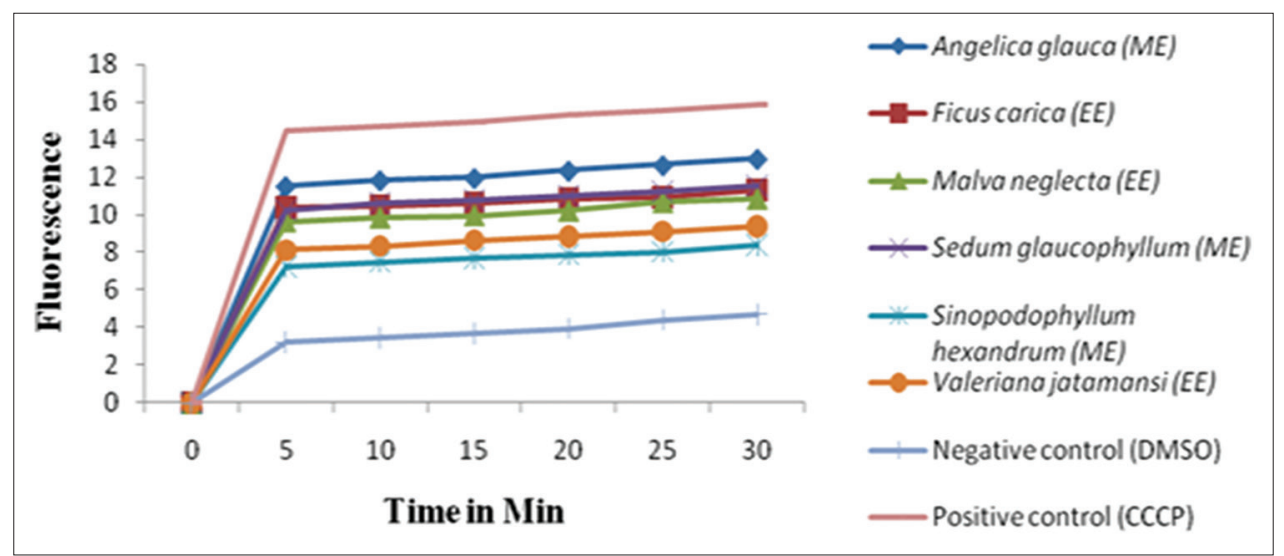

Fig. 3: Effect of plant extracts on accumulation of ethidium bromide by 8325-4 wild type strain

the PEs selected on the basis of synergistic activity in the current study showed efflux pump inhibitory activity, but maximum activity exhibited by A. glauca (ME). Keeping the reference of the same, the present investigations results followed the Rana et al., 2014 [34], in which the plants Artemisia absinthium, Berberis plant, Geranium caespitosum, R. officinalis, Dalea versicolor, Lycopus europaeus, Thymus vulgaris, Jatropha elliptica, Piper nigrum, Piper longum, Salix alba, Momordica balsamina, Lupinus argenteus, Artemisia annua, Ipomoea murucoides, Herissantia tiubae, Mezoneuron benthamianum, and Securinega virosa exhibited NorA efflux pump inhibitory activity. Hence, the present investigations added an extra knowledge of efflux pump inhibitory activity for the tested plants collected from Western Himalayan region of India. The bioactive compounds having efflux inhibitory activity of $A$. glauca (ME) can be used in future as adjutants with antibiotics.

\section{CONCLUSION}

The above study can be concluded that the problem of antimicrobial resistance due to efflux is growing, and the outlook for the use of antimicrobial drugs against $S$. aureus in the future is still uncertain. The synergistic effect of the association of antibiotic with efflux pump inhibitors isolated from plant sources against $S$. aureus leads to new choices for the treatment of Staphylococcal diseases. This study 


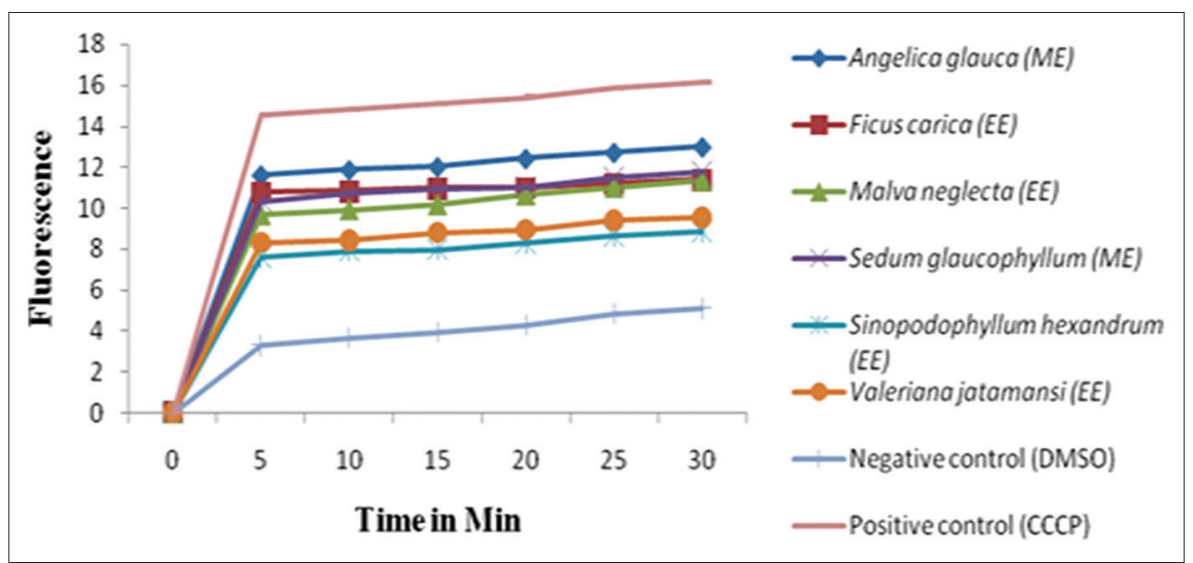

Fig. 4: Effect of plant extracts on accumulation of ethidium bromide by 1758 knockout strain

has shown that a ME of A. glauca exhibits potentials of synergy in combination with selected antibiotics against $S$. aureus strains, often presenting with problems of drug resistance (mainly due to efflux pumps). Moreover, this study established a good base for developing future, NorA efflux pump inhibitors from A. glauca (ME) as an adjuvant of antibiotics.

\section{ACKNOWLEDGMENTS}

The authors are thankful to Dr. Kim Lewis, Northeastern University, Boston, USA for providing strains S. aureus 8325-4 (wild type) and K1758 (NorA Knockout), K2378 (NorA overexpressing).

\section{REFERENCES}

1. Collier LH, Balows A, Sussman M. Topley and Wilson's Microbiology and Microbial Infections, Systematic Bacteriology. $2^{\text {nd }}$ ed. New York, NY: Oxford University Press; 1999.

2. Metri BC, Peerapur BV, Jyothi P. Drug resistance patterns of clinical isolates of Staphylococcus aureus in tertiary care center of South India. Int J Pharm Pharm Sci 2015;7:70-2.

3. Schito GC. The importance of the development of antibiotic resistance in Staphylococcus aureus. Clin Microbiol Infect 2006;12 Suppl 1:3-8.

4. Goldstein F. The potential clinical impact of low-level antibiotic resistance in Staphylococcus aureus. J Antimicrob Chemother 2007;59(1):1-4

5. Piddock LJ. Clinically relevant chromosomally encoded multidrug resistance efflux pumps in bacteria. Clin Microbiol Rev 2006;19(2):382-402.

6. Stavri M, Piddock LJ, Gibbons S. Bacterial efflux pump inhibitors from natural sources. J Antimicrob Chemother 2007;59(6):1247-60.

7. Neyfakh AA, Bidnenko VE, Chen LB. Efflux-mediated multidrug resistance in Bacillus subtilis: Similarities and dissimilarities with the mammalian system. Proc Natl Acad Sci U S A 1991;88(11):4781-5.

8. Markham PN, Westhaus E, Klyachko K, Johnson ME, Neyfakh AA. Multiple novel inhibitors of the NorA multidrug transporter of Staphylococcus aureus. Antimicrob Agents Chemother 1999;43(10):2404-8.

9. Lomovskaya O, Warren MS, Lee A, Galazzo J, Fronko R, Lee M, et al. Identification and characterization of inhibitors of multidrug resistance efflux pumps in Pseudomonas aeruginosa: Novel agents for combination therapy. Antimicrob Agents Chemother 2001;45(1):105-16.

10. Kannusamy G, Rengaswamy G. In vitro antibacterial activities of Opuntia Ficus-indica stem and fruit extracts using disc diffusion method. Int Curr Pharm J 2016;8(2):68-9.

11. Koduru SV, Grierson DS, Afolayan AJ. Ethnobotanical information of medicinal plants used for treatment of cancer in the Eastern Cape province, South Africa. Curr Sci 2007;92:906-8.

12. Handzlik J, Matys A, Kiec-Kononowicz K. Recent advances in multidrug resistance (MDR) efflux pump inhibitors of gram-positive bacteria S. aureus. Antibiotics (Basel) 2013;2(1):28-45.

13. Sultana B, Anwar F, Ashraf M. Effect of extraction solvent/technique on the antioxidant activity of selected medicinal plant extracts. Molecules 2009;14(6):2167-80.

14. Mandal S, Mandal MD, Pal NK, Saha K. Synergistic anti-Staphylococcus aureus activity of amoxicillin in combination with Emblica officinalis and Nymphae odorata extracts. Asian Pac J Trop Dis 2010;60:711-4.

15. Belofsky G, Carreno R, Lewis K, Ball A, Casadei G, Tegos GP. Metabolites of the "smoke tree", Dalea spinosa, potentiate antibiotic activity against multidrug-resistant Staphylococcus aureus. J Nat Prod 2006;69(2):261-4.

16. Zechini B, Versace I. Inhibitors of multidrug resistant efflux systems in bacteria. Recent Pat Antiinfect Drug Discov 2009;4(1):37-50.

17. Ibezim EC, Esimone CO, Nnamani PO, Onyishi IV, Brown SA, Obodo SE. In vitro study of the interaction between some fluoroquinolones and extracts of Kola nitida seed. Afr J Biotechnol 2006;5:1781-4.

18. Yang ZC, Wang BC, Yang XS, Wang Q, Ran L. The synergistic activity of antibiotics combined with eight traditional Chinese medicines against two different strains of Staphylococcus aureus. Colloids Surf B Biointerfaces 2005;41(2-3):79-81.

19. Aqil F, Khan MS, Owais M, Ahmad I. Effect of certain bioactive plant extracts on clinical isolates of beta-lactamase producing methicillin resistant Staphylococcus aureus. J Basic Microbiol 2005;45(2):106-14

20. Adwan GM, Shanab BA, Adwan KM. In vitro activity of certain drugs in combination with plant extracts against Staphylococcus aureus infections. Pak J Med Sci 2008;24(4):541-4.

21. Betoni JE, Mantovani RP, Barbosa LN, Di Stasi LC, Fernandes A Jr. Synergism between plant extract and antimicrobial drugs used on Staphylococcus aureus diseases. Mem Inst Oswaldo Cruz 2006;101(4):387-90.

22. Esimone $\mathrm{CO}$, Iroha IR, Ibezim $\mathrm{EC}$, Okeh $\mathrm{CO}$, Okpana $\mathrm{EM}$. In vitro evaluation of the interaction between tea extracts and penicillin $G$ against Staphylococcus aureus. Afr J Biotechnol 2006;5:1082-6.

23. Darwish RM, Aburjai T, Al-Khalil S, Mahafzah A. Screening of antibiotic resistant inhibitors from local plant materials against two different strains of Staphylococcus aureus. J Ethnopharmacol 2002;79(3):359-64.

24. Braga LC, Leite AA, Xavier KG, Takahashi JA, Bemquerer MP, Chartone-Souza E, et al. Synergic interaction between pomegranate extract and antibiotics against Staphylococcus aureus. Can J Microbiol 2005;51(7):541-7.

25. Yam TS, Hamilton-Miller JM, Shah S. The effect of a component of tea (Camellia sinensis) on methicillin resistance, PBP2' synthesis, and beta-lactamase production in Staphylococcus aureus. J Antimicrob Chemother 1998;42(2):211-6.

26. Sibanda T, Okok AI. The challenges of overcoming antibiotic resistance: Plant extracts as potential sources of antimicrobial and resistance modifying agents. Afr J Biotechnol 2007;6(25):2886-96.

27. Gibbons S, Oluwatuyi M, Veitch NC, Gray AI. Bacterial resistance modifying agents from Lycopus europaeus. Phytochemistry 2003;62(1):83-7.

28. Dickson RA, Houghton PJ, Hylands PJ, Gibbons S. Antimicrobial, resistance-modifying effects, antioxidant and free radical scavenging activities of Mezoneuron benthamianum Baill. Securinega virosa Roxb. \&Wlld. and Microglossa pyrifolia Lam. Phytother Res 2006;20(1):41-5.

29. Chang PC, Li HY, Tang HJ, Liu JW, Wang JJ, Chuang YC. In vitro synergy of baicalein and gentamicin against vancomycin-resistant Enterococcus. J Microbiol Immunol Infect 2007;40(1):56-61.

30. Horiuchi K, Shiota S, Kuroda T, Hatano T, Yoshida T, Tsuchiya T. 
Potentiation of antimicrobial activity of aminoglycosides by carnosol from Salvia officinalis. Biol Pharm Bull 2007;30(2):287-90.

31. Ahmad I, Aqil F. In vitro efficacy of bioactive extracts of 15 medicinal plants against ESbetaL-producing multidrug-resistant enteric bacteria. Microbiol Res 2007;162(3):264-75.

32. Nascimento GG, Locatelli J, Freitas PC, Silva GL. Antibacterial activity of plant extracts and phytochemicals on antibiotic-resistant bacteria. Braz J Microbial 2000;31:247-56.

33. Hussaini RA, Adel MM. Antimicrobial and antiquorum sensing activity of different parts of Lourus nobilis L. extracts. J Med 2009;43(4):286-98

34. Rana T, Singh S, Kaur N, Pathania K, Farooq U. A review on efflux pump inhibitors of medically important bacteria from plant sources. Int J Pharm Sci Rev Res 2014;26(2):101-11. 